\title{
Long-term outcomes in patients with non-alcoholic fatty liver disease: further evidence that a multidisciplinary and patient-centred approach to treatment is needed
}

\author{
Giovanni Targher
}

Section of Endocrinology, Diabetes and Metabolism, Department of Medicine, University and Azienda Ospedaliera Universitaria Integrata of Verona, Verona, Italy

Correspondence to: Prof. Giovanni Targher, MD. Section of Endocrinology, Diabetes and Metabolism, Department of Medicine, University and Azienda Ospedaliera Universitaria Integrata of Verona, Verona, Italy. Email: giovanni.targher@univr.it.

Comment on: Sanyal AJ, Van Natta ML, Clark J, et al. Prospective Study of Outcomes in Adults with Nonalcoholic Fatty Liver Disease. N Engl J Med 2021;385:1559-69.

Submitted Dec 13, 2021. Accepted for publication Dec 28, 2021.

doi: $10.21037 / \mathrm{hbsn}-21-528$

View this article at: https://dx.doi.org/10.21037/hbsn-21-528

The prevalence of non-alcoholic fatty liver disease (NAFLD) is thought to be on the rise globally (1). An updated meta-analysis reported that in 2019 the pooled global prevalence of NAFLD was $29.8 \%$ [ $95 \%$ confidence interval (CI): 28.6-31.1\%] with the highest NAFLD prevalence observed in South America and North America (2). From 1991-2019, trend analysis also showed that NAFLD prevalence increased from $~ 22 \%$ to $37 \%$ (with yearly increase of $0.7 \%$ ), with South America showing the most rapid change of $2.7 \%$ per year followed by the Europe at $1.1 \%(2)$.

To date, our knowledge(s) of NAFLD-related long-term clinical outcomes is based largely on retrospective analyses of population-based or hospital-based cohort studies that are limited by the absence of histological confirmation of NAFLD, whereas the few published retrospective studies with liver biopsy data are limited by their relatively small sample size, short duration of follow-up, and variable assessments of disease status and outcomes (3). Thus, there is currently a paucity of good quality data on the rates and types of long-term clinical outcomes among patients with NAFLD.

In a prospective observational study recently published in the New England Fournal of Medicine, Prof. Sanyal and colleagues provided interesting data on the long-term clinical outcomes in adults with NAFLD (4). Using the NAFLD Database Study phase 2 that is a prospective, noninterventional registry of the Non-Alcoholic Steatohepatitis Clinical Research Network (NASH-CRN), these researchers prospectively followed for a median of 4 years a carefully selected cohort of 1,773 United States adults with biopsy-proven NAFLD (1,141 women and 632 men with a mean age of 52 years, most of whom were White and of European ancestry) (4). The clinical and laboratory data were obtained at enrollment and then at 48-week intervals in a prospective, protocol-mandated approach and at the time of any liver biopsies performed as local standard care. The principal outcomes of the study included all-cause death, hepatic decompensation, a Model for End-stage Liver Disease (MELD) score of 15 or greater, hepatocellular carcinoma, extra-hepatic cancers, cardiovascular events (including myocardial infarction, unstable angina, sudden death, revascularization interventions, and hospitalization for heart failure), and cerebrovascular events (including transient ischemic attack and ischemic stroke). New onsets of coexisting conditions such as type 2 diabetes, hypertension and chronic kidney disease were defined by standard criteria and also tracked as clinical outcomes of interest. At baseline, from a histological point of view, 75\% of the 1,773 patients had borderline or definite NASH, and $25 \%$ had fatty liver without NASH. A total of 536 patients (30\%) had 'bridging' fibrosis [stage F3 (369 patients)] or cirrhosis [stage F4 (167 patients)].

In their study the researchers found that during a median follow-up of 4 years, 47 of the 1,773 patients with NAFLD (2.7\%) died, an event rate of 0.57 per 100 person-years. The main causes of death among these patients were liver- 
related and cardiovascular complications, followed by extrahepatic cancers and sepsis. New-onset arterial hypertension (7.8 events per 100 person-years) was the most common extra-hepatic outcome, followed by type 2 diabetes mellitus (4.8 events per 100 person-years), chronic kidney disease (2.5 events per 100 person-years), cardiac events (0.8 incident events per 100 person-years), extrahepatic cancers (0.8 events per 100 person-years), and cerebrovascular events ( 0.4 events per 100 person-years). Interestingly, the researchers found that the risk of death from any cause increased progressively with increasing fibrosis stages, from 0.32 per 100 person-years for stage F0 to $\mathrm{F} 2$ to 0.89 per 100 person-years for stage $\mathrm{F} 3$ and to 1.76 deaths per 100 person-years for stage F4, respectively. The incidence of liver-related complications (defined as hepatic decompensation events or hepatocellular carcinoma) was also higher among patients with stage $\mathrm{F} 3$ or $\mathrm{F} 4$ fibrosis than among those with stage F0 to F2 fibrosis. In addition, compared to those with stage F0 to F2 fibrosis, patients with stage $\mathrm{F} 4$ fibrosis had a higher incidence of type 2 diabetes, hypertension, and chronic kidney disease. The incidence of cardiovascular events and extra-hepatic cancers was similar across fibrosis stages (4). In their study the researchers also found that the hazard ratio for all-cause death among patients with stage F2 fibrosis was 2.3 (95\% CI: 0.8-7.0), compared with those with stage F0 or F1. However, as given the low event rates and wide confidence intervals, these data cannot be used to infer a greater risk of all-cause death. Further larger prospective studies with longer followups are needed to confirm or refute these data; as written by the same researchers, such data will be clinically important to better define the benefits of treatment in NASH patients with stage F2 fibrosis and to define whether benefits accrue from lack of progression alone or also from regression of the liver fibrosis stage (4).

Overall, the results of this important prospective cohort study conducted in the USA corroborate the findings of previous retrospective observational studies conducted in other countries, and provide further strong evidence that NAFLD may progress into NASH and its associated liverrelated complications (5-9). Unsurprisingly, the results of this study confirm what we see in our clinical practice, i.e., the severity of biopsy-confirmed fibrosis is a key prognostic marker of both mortality and liver-related morbidity in NAFLD. The results of this study also confirm the findings of recent meta-analyses supporting a significant association between the severity of NAFLD (especially higher fibrosis stage) and the risk of developing type 2 diabetes and chronic kidney disease $(10,11)$. However, the results of this study appear to be at variance with those of other reports supporting a significant positive association between the risk of fatal and non-fatal cardiovascular outcomes and the severity of NAFLD, especially the stage of fibrosis $(12,13)$. It is possible to hypothesize that this apparent discrepancy is due to a low incidence rate of fatal and non-fatal cardiovascular events observed in the study by Sanyal et al. (4) that was about three-fold lower (i.e., event rate 0.83 vs. 2.43 per 100 person-years) than that observed in a recently published population-based cohort study in Sweden (13). Specifically, in this nationwide histology cohort that included all Swedish adults with histologically-confirmed NAFLD and without pre-existing cardiovascular disease at baseline (1966-2016, $\mathrm{n}=10,422)$ and 46,517 population controls matched for age, sex, calendar year and county, Simon et al. (13) found that patients with NAFLD had a higher risk of incident major adverse cardiovascular events than controls (2.43 vs. 1.60 per 100 person-years; adjustedhazard ratio $=1.63 ; 95 \%$ CI: $1.56-1.70$ ), independently of common cardiometabolic risk factors, over a median of 13.6 years of follow-up. Furthermore, the risk of major adverse cardiovascular events increased progressively with worsening NAFLD severity, with the highest incidence observed with cirrhosis (13).

Prof. Sanyal and colleagues have discussed in a balanced way the most important strengths and limitations of their study (4). In particular, among the major study limitations, it is important to remember that the study lacked a nonsteatotic control group and the generalizability of these data may be limited by the inclusion of a predominantly White population of European ancestry and by the selection bias that is inherent in cohort studies conducted at tertiary gastroenterology care centers (with the inclusion of people who had a liver biopsy at enrollment). Also, the widths of the confidence intervals around the hazard ratios have not been adjusted for multiplicity and should not be used to infer generalizable effects. In addition, as recognized by the same investigators, most deaths occurred in centers outside the study sites, and the quality of the data available to determine the cause of death was mixed. Finally, as summarized in Table 1, it is also important to underline that the length of the study follow-up was relatively short (i.e., median of 4 years) and, most importantly, the rate of allcause death was much lower compared to that observed in other large cohorts of patients with biopsy-confirmed NAFLD with longer follow-up durations $(4-7,9)$. For example, the rate of all-cause death was about 5 times lower 
Table 1 Principal retrospective and prospective cohort studies of patients with biopsy-confirmed NAFLD examining the rate of all-cause mortality (ordered by publication year)

\begin{tabular}{|c|c|c|c|c|}
\hline Authors, year (ref.) & Study characteristics & $\begin{array}{l}\text { Mean age, female } \\
\text { sex, White race }\end{array}$ & Follow-up duration & $\begin{array}{l}\text { All-cause death (n. events } / n \text {. at } \\
\text { risk, rate per } 100 \text { person-years) }\end{array}$ \\
\hline $\begin{array}{l}\text { Angulo et al., } \\
2015 \text { (5) }\end{array}$ & $\begin{array}{l}\text { Retrospective multi-national cohort } \\
\text { of } 619 \text { adults with biopsy-proven } \\
\text { NAFLD ( } 46 \% \text { with definite or } \\
\text { borderline NASH) }\end{array}$ & $\begin{array}{l}49 \text { years, } \\
63 \% \text { women, } \\
88 \% \text { White }\end{array}$ & Median 12.6 years & $193 / 619(31 \%)$ \\
\hline $\begin{array}{l}\text { Hagström et al., } \\
2017 \text { (6) }\end{array}$ & $\begin{array}{l}\text { Retrospective cohort of } 646 \text { Sweden } \\
\text { adults with biopsy-proven NAFLD } \\
\text { (59\% with NASH) }\end{array}$ & $\begin{array}{l}48 \text { years, } \\
52 \% \text { women, } \\
80 \% \text { White }\end{array}$ & Mean 20 years & $214 / 646(33 \%)$ \\
\hline $\begin{array}{l}\text { Vilar-Gomez et al., } \\
2018 \text { (7) }\end{array}$ & $\begin{array}{l}\text { Retrospective multi-national cohort of } \\
458 \text { adults with biopsy-proven NAFLD } \\
(100 \% \text { with fibrosis stage F3 or F4) }\end{array}$ & $\begin{array}{l}56 \text { years, } \\
63 \% \text { women, } \\
88 \% \text { White }\end{array}$ & Mean 5.5 years & $37 / 458(8 \%)$ \\
\hline $\begin{array}{l}\text { Simon et al., } \\
2021 \text { (9) }\end{array}$ & $\begin{array}{l}\text { Retrospective nationwide cohort of } \\
10,568 \text { Sweden adults with } \\
\text { biopsy-proven NAFLD } \\
\text { ( } 27 \% \text { with NASH) }\end{array}$ & $\begin{array}{l}52 \text { years, } \\
45 \% \text { women, } \\
100 \% \text { White }\end{array}$ & Median 14.2 years & $\begin{array}{l}4,338 / 10,568(41 \%), 2.86 \text { rate } \\
\text { per } 100 \text { person-years }\end{array}$ \\
\hline
\end{tabular}

NAFLD, non-alcoholic fatty liver disease; NASH, non-alcoholic steatohepatitis.

in the study by Sanyal et al. (4) compared to that observed in the Sweden cohort study by Simon et al. (9) (event rate $0.57 v s .2 .86$ per 100 person-years).

That said, although further evidence from well-reported cohort studies is needed to better elucidate the prognostic impact of fibrosis stage on long-term clinical outcomes in people with NAFLD, the results of this interesting study by Sanyal et al. (4) provide further evidence that patients with more advanced NAFLD need to be monitored carefully and that a multidisciplinary and holistic approach to the treatment of NAFLD is needed, where not only is the management and treatment of liver disease considered, but also the increased risk of cardiometabolic and other extrahepatic complications (14).

\section{Acknowledgments}

Funding: None.

\section{Footnote}

Provenance and Peer Review: This article was commissioned by the editorial office, Hepatobiliary Surgery and Nutrition. The article did not undergo external peer review.

Conflicts of Interest: The author has completed the ICMJE uniform disclosure form (available at https://hbsn. amegroups.com/article/view/10.21037/hbsn-21-528/coif). The author has no conflicts of interest to declare.

Ethical Statement: The author is accountable for all aspects of the work in ensuring that questions related to the accuracy or integrity of any part of the work are appropriately investigated and resolved.

Open Access Statement: This is an Open Access article distributed in accordance with the Creative Commons Attribution-NonCommercial-NoDerivs 4.0 International License (CC BY-NC-ND 4.0), which permits the noncommercial replication and distribution of the article with the strict proviso that no changes or edits are made and the original work is properly cited (including links to both the formal publication through the relevant DOI and the license). See: https://creativecommons.org/licenses/by-nc-nd/4.0/.

\section{References}

1. Karlsen TH, Sheron N, Zelber-Sagi S, et al. The EASLLancet Liver Commission: protecting the next generation of Europeans against liver disease complications and premature mortality. Lancet 2022;399:61-116.

2. Le MH, Yeo YH, Li X, et al. 2019 global NAFLD 
prevalence - A systematic review and meta-analysis. Clin Gastroenterol Hepatol 2021. [Epub ahead of print]. doi: 10.1016/j.cgh.2021.12.002.

3. Mantovani A, Scorletti E, Mosca A, et al. Complications, morbidity and mortality of nonalcoholic fatty liver disease. Metabolism 2020;111S:154170.

4. Sanyal AJ, Van Natta ML, Clark J, et al. Prospective Study of Outcomes in Adults with Nonalcoholic Fatty Liver Disease. N Engl J Med 2021;385:1559-69.

5. Angulo P, Kleiner DE, Dam-Larsen S, et al. Liver Fibrosis, but No Other Histologic Features, Is Associated With Long-term Outcomes of Patients With Nonalcoholic Fatty Liver Disease. Gastroenterology 2015;149:389-97.e10.

6. Hagström H, Nasr P, Ekstedt M, et al. Fibrosis stage but not NASH predicts mortality and time to development of severe liver disease in biopsy-proven NAFLD. J Hepatol 2017;67:1265-73.

7. Vilar-Gomez E, Calzadilla-Bertot L, Wai-Sun Wong V, et al. Fibrosis Severity as a Determinant of Cause-Specific Mortality in Patients With Advanced Nonalcoholic Fatty Liver Disease: A Multi-National Cohort Study. Gastroenterology 2018;155:443-457.e17.

8. Taylor RS, Taylor RJ, Bayliss S, et al. Association Between Fibrosis Stage and Outcomes of Patients With Nonalcoholic Fatty Liver Disease: A Systematic Review and
Meta-Analysis. Gastroenterology 2020;158:1611-1625.e12.

9. Simon TG, Roelstraete B, Khalili H, et al. Mortality in biopsy-confirmed nonalcoholic fatty liver disease: results from a nationwide cohort. Gut 2021;70:1375-82.

10. Mantovani A, Petracca G, Beatrice G, et al. Non-alcoholic fatty liver disease and risk of incident diabetes mellitus: an updated meta-analysis of 501022 adult individuals. Gut 2021;70:962-9.

11. Mantovani A, Petracca G, Beatrice G, et al. Non-alcoholic fatty liver disease and risk of incident chronic kidney disease: an updated meta-analysis. Gut 2022;71:156-62.

12. Mantovani A, Csermely A, Petracca G, et al. Nonalcoholic fatty liver disease and risk of fatal and nonfatal cardiovascular events: an updated systematic review and meta-analysis. Lancet Gastroenterol Hepatol 2021;6:903-13.

13. Simon TG, Roelstraete B, Hagström H, et al. Nonalcoholic fatty liver disease and incident major adverse cardiovascular events: results from a nationwide histology cohort. Gut 2021. [Epub ahead of print]. doi: 10.1136/ gutjnl-2021-325724.

14. Targher G, Tilg H, Byrne CD. Non-alcoholic fatty liver disease: a multisystem disease requiring a multidisciplinary and holistic approach. Lancet Gastroenterol Hepatol 2021;6:578-88.

Cite this article as: Targher G. Long-term outcomes in patients with non-alcoholic fatty liver disease: further evidence that a multidisciplinary and patient-centred approach to treatment is needed. HepatoBiliary Surg Nutr 2022;11(1):143146. doi: 10.21037/hbsn-21-528 